\title{
Familial Intrahepatic Cholestatic Jaundice in Infancy
}

\author{
O. P. GRAY and R. A. SAUNDERS \\ From the Department of Child Health, Welsh National School of Medicine, Llandough Hospital, Penarth, Glam.
}

Recurrent jaundice due to intrahepatic cholestasis is reported most often in adults. Some varieties are familial and are associated with failure of excretion of conjugated bilirubin by the liver cell. The original descriptions of these types given by Rotor, Manahan, and Florentin (1948) and Dubin and Johnson (1954) concerned patients with a benign recurrent jaundice. The diseases described by these authors differ in liver histology and certain liver function tests. The fundamental defect appears to be an inability to transport conjugated bilirubin across the cell membrane between the liver cell and the bile canaliculus. We report two sisters both of whom died under 3 years of age from a malignant variety of intrahepatic cholestasis due to a similar difficulty in bile excretion. Both children were born and lived in South Wales; the mother is a native of Wales, but the father is Irish. The parents are not related. The father's uncle had jaundice on several occasions in adult life, but further details are not available.

\section{Case Histories}

Case 1. This girl, the first in the family, was born after a normal full-term pregnancy and delivery on February 21, 1959; birth weight $6 \mathrm{lb} .14 \mathrm{oz} .(3 \cdot 1 \mathrm{~kg}$.). The mother stated that the baby was jaundiced shortly after birth and that the motions were pale and the urine dark. Jaundice was present at the age of 7 weeks when she was admitted to hospital. Her general condition then was good, the liver was palpable $1 \frac{1}{2}$ in. $(3 \cdot 8 \mathrm{~cm}$.) below the costal margin, but the spleen was not felt. One of the most troublesome features was the persistent itching which caused the child to scratch day and night. This pruritus was constantly present throughout her life. The jaundice improved at first but increased again three months later. The liver gradually increased in size; the stools remained pale and the urine dark.

At the age of 8 months a laparotomy was performed because of the continuing unexplained obstructive jaundice. A liver biopsy was taken. The liver was enlarged but looked normal. The gall-bladder was distended. The bile passages were normal. A cholangiogram done during the laparotomy showed a free

Received November 8, 1965. passage into the duodenum and good retrograde filling of the small intrahepatic biliary passages. The liver biopsy showed normal liver cells, bile-ducts, and portal tract. There was no abnormal pigment in the hepatic cells. There was occasional bile plugging of the canaliculi. The veins in the portal tract and the central veins were dilated.

After operation the jaundice deepened for a few weeks and then improved. At the age of 14 months the jaundice once again deepened, the liver enlarged, and the spleen became palpable. She had frequent nose bleeds requiring cauterization of the vessels and two blood transfusions.

At the age of 2 years 7 months she was readmitted to hospital because the abdomen had become prominent and there was difficulty with breathing. The abdomen was tense; the liver was palpable 2 in. $(5 \mathrm{~cm}$.) below the costal margin; there was shifting dullness and a fluid thrill. She gradually deteriorated over the next three weeks and died. Permission for necropsy was refused.

Case 2. This child, the second in the family, was born at home on February 17, 1961, after a normal delivery, and weighed $6 \mathrm{lb} .8 \mathrm{oz}$. $(2,948 \mathrm{~g}$.). She was admitted to hospital at the age of a few days because of vomiting which subsided after a fortnight. At the age of 6 weeks she was noticed to be jaundiced. For the next three months the jaundice varied in intensity, and was associated with dark urine and loose offensive pale stools. At the age of 5 months she was readmitted to hospital. She weighed only $8 \mathrm{lb} .8 \mathrm{oz}$. ( $3.9 \mathrm{~kg}$.), was jaundiced, and frequently scratched. The intense pruritis was present throughout the child's life and was the feature that caused most worry to the child and her mother. The liver was palpable 1 in. $(2 \cdot 5 \mathrm{~cm}$.) below the costal margin, and the spleen tip could be felt. There was no xanthoma, spider naevus, or hepatic bruit. Because of the continued obstructive jaundice and the sister's history, a laparotomy was performed, when the child was 6 months.

The liver was smooth, enlarged, and firmer than normal. A biopsy was taken. The gall-bladder, cystic duct, and common bile-duct were normal. The gallbladder was opened and a small amount of green bile was present. An operative cholangiogram was made via a tube in the gall-bladder, which showed normal intraand extrahepatic biliary passages. It was, therefore, presumed that the obstruction was at cellular or canalicular level. A tube was placed from the gall- 


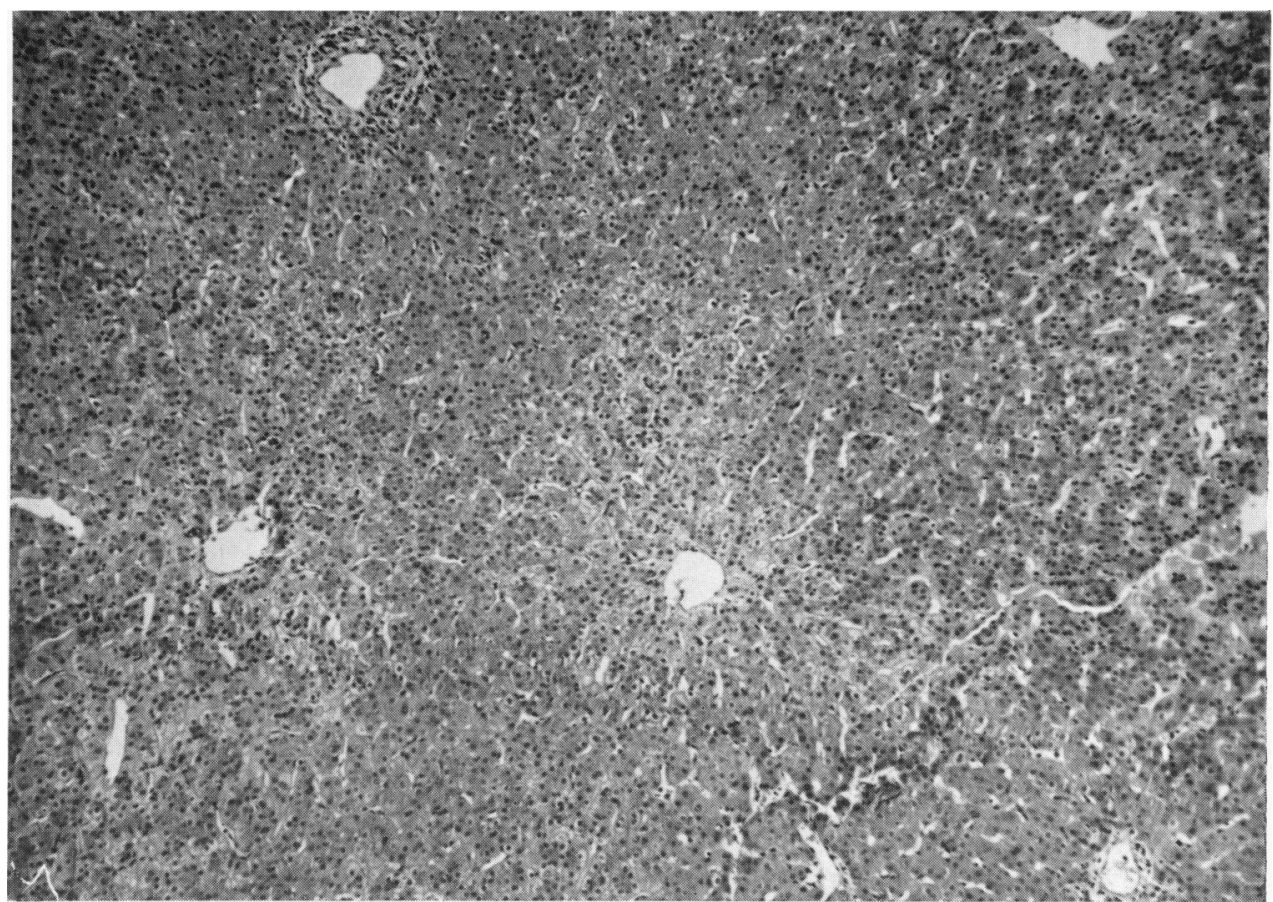

Fig. 1.-Liver biopsy (Case 2) shows normal liver parenchyma. ( $\quad$ 140.)

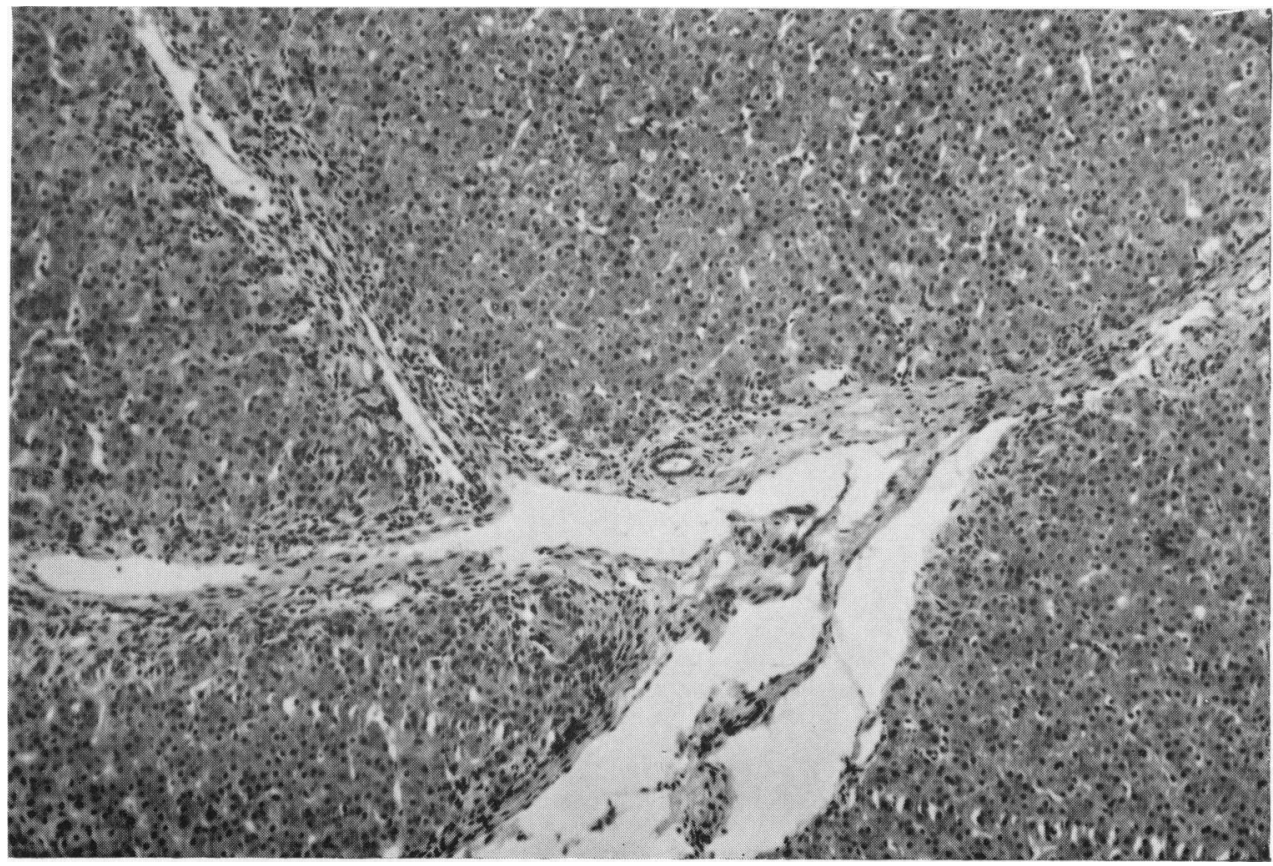

Fig. 2.-Liver biopsy (Case 2) shows slight increase in portal fibrous tissue. $(\times 180$. 
bladder and allowed to drain for three days. A total of $55 \mathrm{ml}$. of bile drained through this tube.

Histology (Dr. F. K. Storring, see Fig. 1 and 2). The lobular architecture of the liver was preserved. The liver parenchyma appeared normal, and there was no evidence of an infective hepatitis or of liver cell regeneration. Occasional portal tracts showed a slight increase of periportal fibrosis with moderate round cell infiltration. Bile plugging was seen in many bile canaliculi; the bile-ducts, however, were patent.

After operation she had a chest infection and was more jaundiced. Two weeks later, when the chest infection had improved the jaundice decreased. An episode of gastro-enteritis six weeks after admission was followed by a further increase in the jaundice.

She was given a high fat and protein diet; bile salts were added for a trial period of one week to see whether the fat absorption could be improved. Unfortunately, the pruritus became more troublesome during this period and so the treatment was stopped. Various antihistamines were given for the pruritus, but none showed any beneficial effect. Moreover, prednisolone $2.5 \mathrm{mg}$. b.d. had no noticeable effect on the jaundice, the serum bilirubin level, or the itching.

At the age of 18 months she was given cholestyramine $2.4 \mathrm{~g}$. a day in three divided doses for three days. This was increased to $4.8 \mathrm{~g}$. a day in three doses for a total of three weeks. There seemed to be a little improvement of the itching. Although the jaundice lessened during this period, it is impossible to say whether this was a natural or cholestyramine-induced remission. During this hospital admission it was noticed that her teeth were a light-brown colour and that her fair hair had an unusual grey sheen. There was abundant hair over the forehead, sides of the face, trunk, and limbs.

Shortly after discharge from hospital she had yet a further episode of her recurring chest infection with increased jaundice. She remained jaundiced and stunted, with hepatosplenomegaly and intense itching until she died at the age of 2 years and 9 months from a bronchopneumonia.

Necropsy (Dr. T. E. Parry, see Fig. 3a, b, c). The relevant findings were as follows.

Abdomen: About $15 \mathrm{oz}$. of clear straw-coloured fluid was present in the peritoneal cavity.

Liver (550 g.): Considerably firmer than normal. The surface of the organ was smooth except for part of the left lobe where it was very finely granular. The cut surface of both lobes was finely granular.

Gall-bladder: Oedematous and contained dark green bile with one or two small amorphous pigmented deposits. The bile-ducts were opened along the entire length. They were patent, thin-walled, smooth, and normal in appearance.

Spleen: $46 \mathrm{~g}$. Slightly enlarged, otherwise normal.

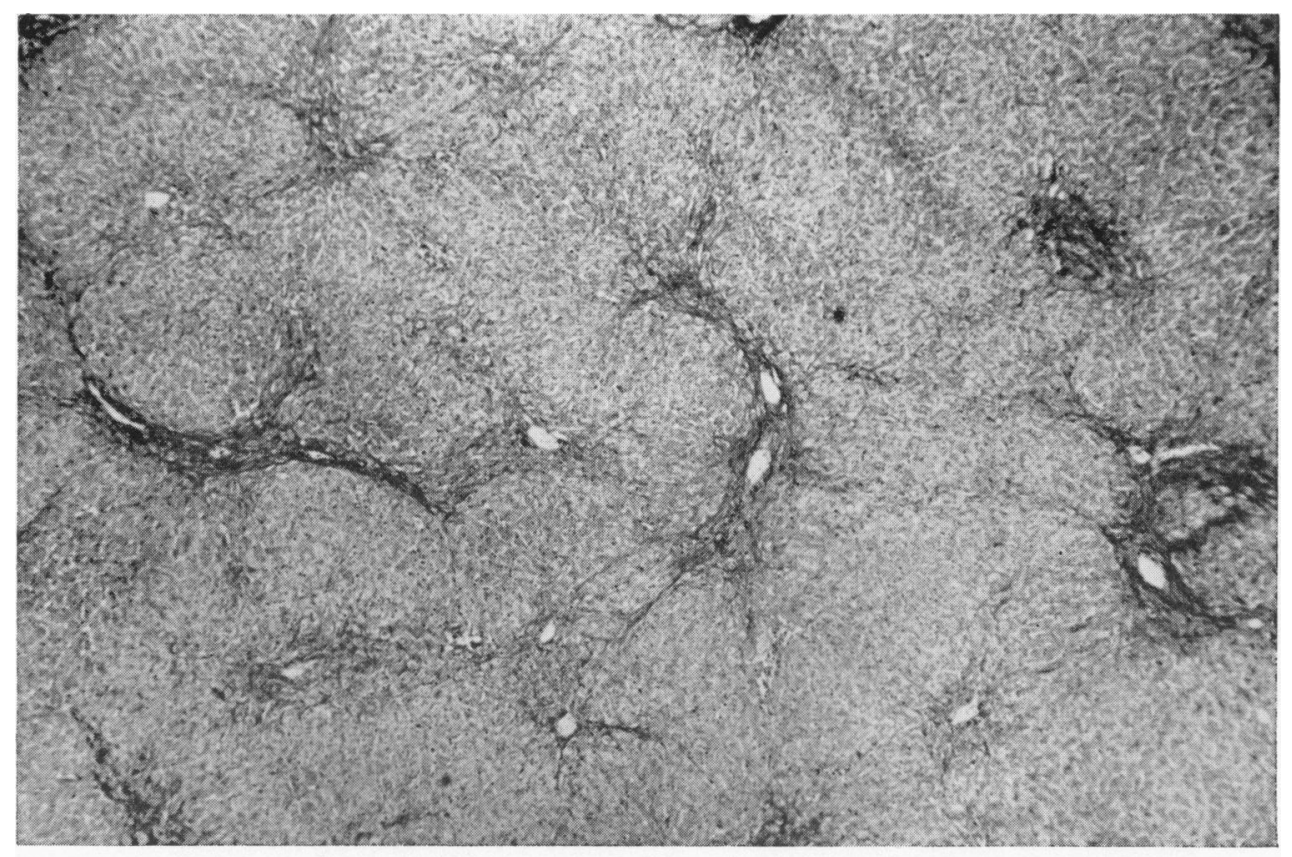

(a)

FIG. 3.-Post-mortem liver histology (Case 2). (a) Low-power view shows well-marked fibrous trabeculae and reduced centrilobular vein. $(\times 40$.) 


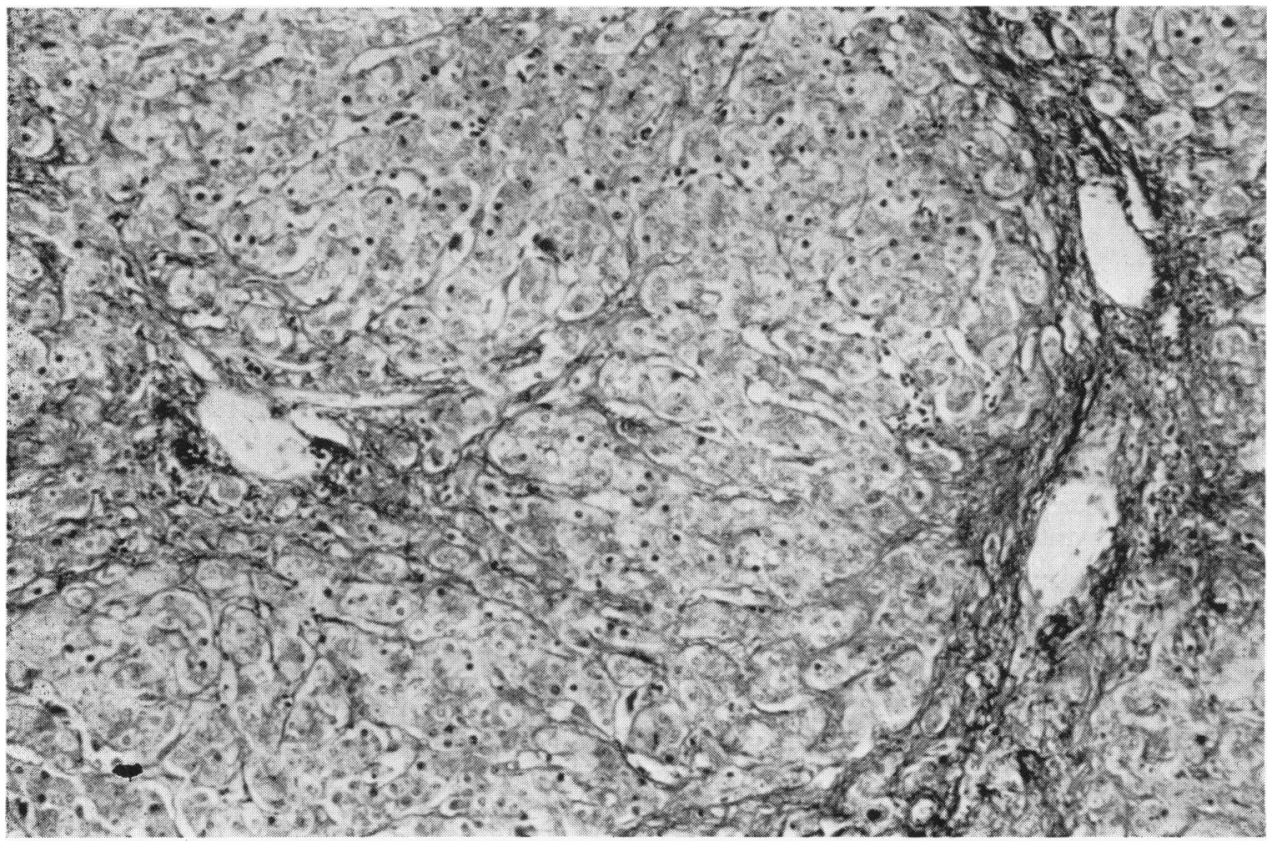

(b)

(b) Medium-power view shows extension of the fibrous network into the liver parenchyma. $(\times 160$.

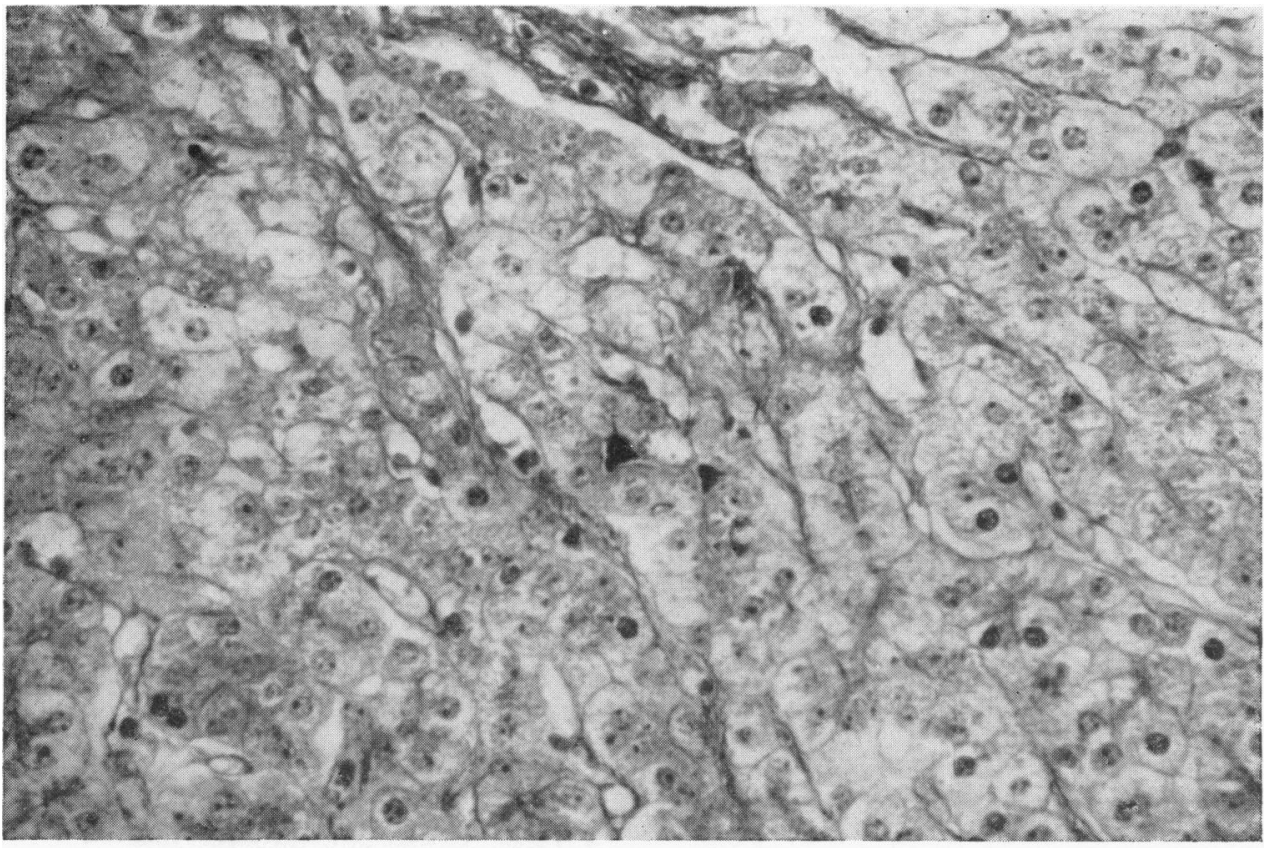

(c)

(c) High-power view shows fine fibrous trabeculae extending along the sinusoids, and there is some plugging of bile canaliculi. $(\times 400$. 


\section{Histology}

Lungs: Base left lower lobe: scanty patchy bronchopneumonia with a fibrinous alveolar exudate containing polymorphs.

Base right lower lobe: more pronounced exudate with fibrin disposed around the alveolar walls with a mononuclear and polymorphonuclear exudate within the alveolar spaces. The appearances in places were similar to those seen in pulmonary hyaline membrane disease.

Liver: The lobular architecture was completely distorted by well-marked fibrous trabeculae surrounding nodules of liver tissue. Most of these were devoid of a centrilobular vein. The fibrous bands extended between the portal tracts themselves and in places between these and the surviving centrilobular veins. Delicate strands of connective tissue extended from this fibrous network into the liver parenchyma, surrounding small groups of liver cells and forming a distinct and prominent lining to the liver sinusoids. The bile canaliculi were not conspicuous, and only occasional bile thrombi were seen. Bile-ducts in the portal tracts were patent and empty. The most prominent histological finding was the extension of fine fibrous trabeculae along the sinusoids.

The clinical and biochemical features of these two sisters were almost identical. Their urine consistently showed the presence of bile pigments and salts. Qualitative tests for urobilinogen gave normal to slightly increased amounts. There was a mild aminoaciduria. The acholic stools had a lowered urobilinogen content from 3.0 to $8.0 \mathrm{mg} . / 100 \mathrm{~g}$. for Case 2 and from 10.0 to $18.0 \mathrm{mg} . / 100 \mathrm{~g}$. for Case 1 . A fat balance on Case 2 showed from 76 to $87 \%$ absorption.

The serum bilirubin levels fluctuated, but gradually

TABLE I

Laboratory Results in Cases 1 and 2

\begin{tabular}{|c|c|c|c|c|c|}
\hline \multicolumn{4}{|c|}{ Investigation } & Case 1 & Case 2 \\
\hline $\begin{array}{l}\text { Bilirubin total (mg./10 } \\
\text { Bilirubin conjugated } \\
\text { Alkaline phosphatase } \\
\text { SGOT } \\
\text { SGPT } \\
\text { Albumin (g./100 ml.) } \\
\text { Globulin (g./100 ml.) } \\
\text { Electrophoresis . . } \\
\text { Zinc turbidity } \ldots \\
\text { Thymol turbidity } \\
\text { Cholesterol } \\
\text { Prothrombin (\%) . . } \\
\text { Haemoglobin (\%) } \\
\text { Pseudocholinesterase } \\
\text { Bromsulphalein (\% re }\end{array}$ & $\begin{array}{l}100 \mathrm{ml} .) \\
\text { (mg./100 m } \\
\text { KA units } \\
\text { S.F. units } \\
\text { S.F. units } \\
\ldots \\
\ldots \\
\ldots \\
\cdots \\
\cdots \\
\cdots \\
\text { (Warburg } \\
\text { etention) }\end{array}$ & $\begin{array}{l}\text { ni.) } \\
\\
\ldots \\
\ldots \\
\ldots \\
\ldots \\
\ldots \\
\ldots \\
\text { units) } \\
\ldots\end{array}$ & \begin{tabular}{l|}
$\cdots$ \\
$\cdots$ \\
$\cdots$ \\
$\cdots$ \\
$\cdots$ \\
$\cdots$ \\
$\cdots$ \\
$\cdots$ \\
$\cdots$ \\
$\cdots$ \\
$\cdots$ \\
$\cdots$
\end{tabular} & $\begin{array}{c}7 \cdot 3 \\
4 \cdot 8 \\
63 \\
55 \\
17 \\
5 \cdot 4 \\
2 \cdot 9 \\
\text { Normal } \\
3 \cdot 2 \\
0 \cdot 8 \\
178 \\
45 \\
80 \\
56 \\
-\end{array}$ & $\begin{array}{c}7 \cdot 5 \\
5 \cdot 0 \\
64 \cdot 5 \\
45 \\
27 \\
5 \cdot 2 \\
2 \cdot 5 \\
\text { Normal } \\
2 \cdot 0 \\
0 \cdot 5 \\
236 \\
70 \\
70 \\
96 \\
59 \cdot 4\end{array}$ \\
\hline
\end{tabular}

TABLE II

Serum Bile Acid Levels (ug./ml.) in Case 2

\begin{tabular}{ll|c|c|c|c}
\hline & & Before & During & After & Normal \\
\hline Dihydroxy &. & $30 \cdot 4$ & $9 \cdot 48$ & $34 \cdot 2$ & $0-1 \cdot 9$ \\
Trihydroxy &. & 27.9 & $1 \cdot 11$ & $16 \cdot 2$ & $0-3 \cdot 4$ \\
\hline
\end{tabular}

rose over the months. There were very high peaks after the biopsies and with the recurrent chest infections. About one-half to two-thirds of the total bilirubin was conjugated. The course of the bilirubin levels is shown in Fig. 4 and 5.

Representative liver function tests are given in Table I, and the fluctuation of the alkaline phosphatase, glutamicpyruvate transaminase, and bilirubin are shown in Fig. 4 and 5. The turbidity tests, serum proteins, and electrophoretic patterns were normal throughout. The alkaline phosphatase was persistently raised, gradually rising with time parallel to the bilirubin levels. The enzymes-serum glutamic oxaloacetic transaminase and glutamic-pyruvate transaminase-were normal for the first eight months of life and they gradually increased in Case 2, whereas, though there was a great increase after operation in Case 1, the levels returned to normal. The pseudocholinesterase was normal in both sisters. The lactic dehydrogenase was 890 units in Case 2, i.e. slightly increased. The other enzymes were also increased at this time.

The lowered prothrombin levels probably reflect a difficulty with vitamin $\mathrm{K}$ absorption. There was considerable bromsulphalein retention in Case 2-59\% in 45 minutes.

In Case 2 the conjugated bilirubin was further fractionated into alkali-stable and alkali-labile forms. The bilirubin glucuronide was estimated by hydrolysis with $\beta$ glucuronidase. The alkali-stable fraction was $50 \%$ and the glucuronide $25 \%$ of the total conjugated bilirubin. The 5-nucleotidase was only slightly raised -9 Bodansky units. The serum bile acids were estimated by the method of Carey (1958) and are shown in Table II.

\section{Discussion}

Icterus, with a green tinging of the skin, the claycoloured stools, and bile-stained urine are evidence of obstructive jaundice. The severe itching, steatorrhoea, and frothy urine also showed that bile salts were retained. However, the obstruction to bile excretion was incomplete, as the jaundice was minimal initially, and some normal bile was obtained from the bile-ducts after operation.

These conclusions were confirmed by the laboratory findings. The urine contained not only bilirubin but also urobilinogen, and though faecal urobilinogen was low it was not completely absent, confirming incomplete obstruction. The bilirubin in the plasma was largely conjugated. The further fractionation of the conjugates showed interesting results. Normally the glucuronide forms about 70 to $75 \%$ of the total, and the alkali-stable fractionthought to be sulphate-is $15 \%$. The other unidentified fraction forms the remaining 10 to $15 \%$. In Case 2, the glucuronide formed only $25 \%$, whereas the alkali-stable fraction was $60 \%$ of the total conjugated bilirubin. Similar findings have 


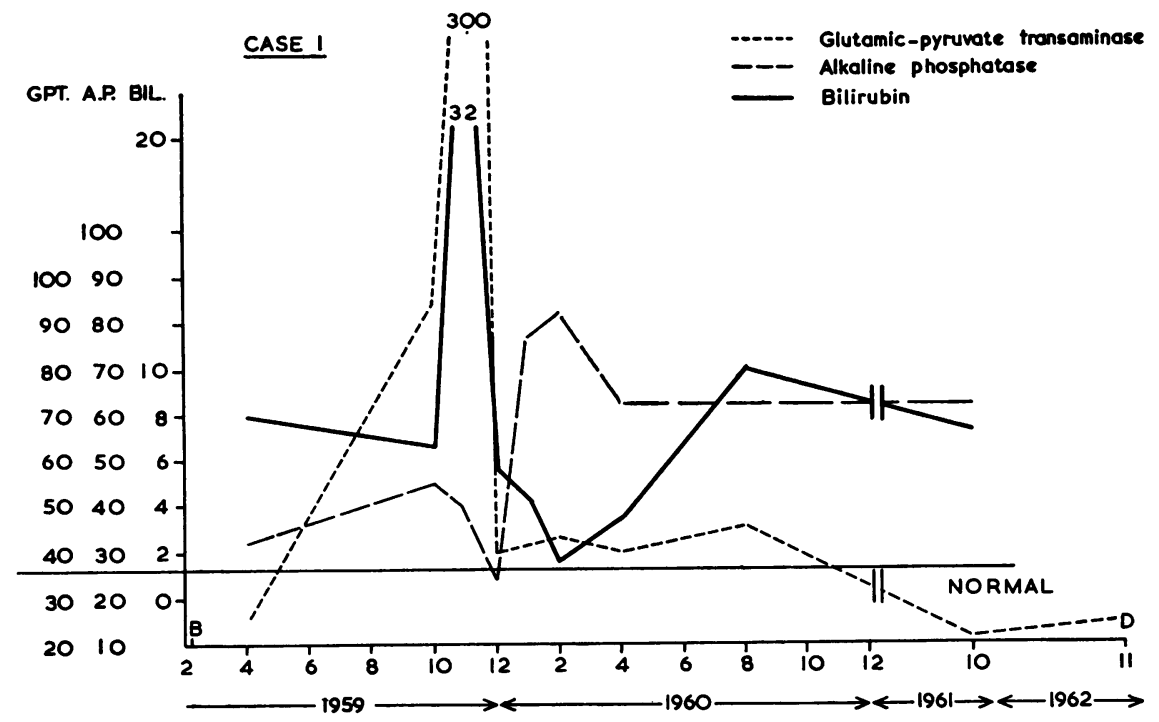

FIG. 4.-Changes in liver function tests of Case 1 with time age.

been reported in both the Dubin-Johnson and Rotor syndromes, though the glucuronide fraction was nearer normal (Schiff, Billing, and Oikawa, 1959; Arias, 1961).

These findings suggest that in addition to the block to excretion of the conjugates there is reduction in the glucuronyl transferase activity and/or an attempt to utilize alternative pathways of conjugation.

The finding of raised serum bile acids confirmed the clinical observations. The extremely high values and the ratio of trihydroxy to dihydroxy bile acids agree with Carey's findings in obstructive jaundice. The marked steatorrhoea-only $76 \%$ fat

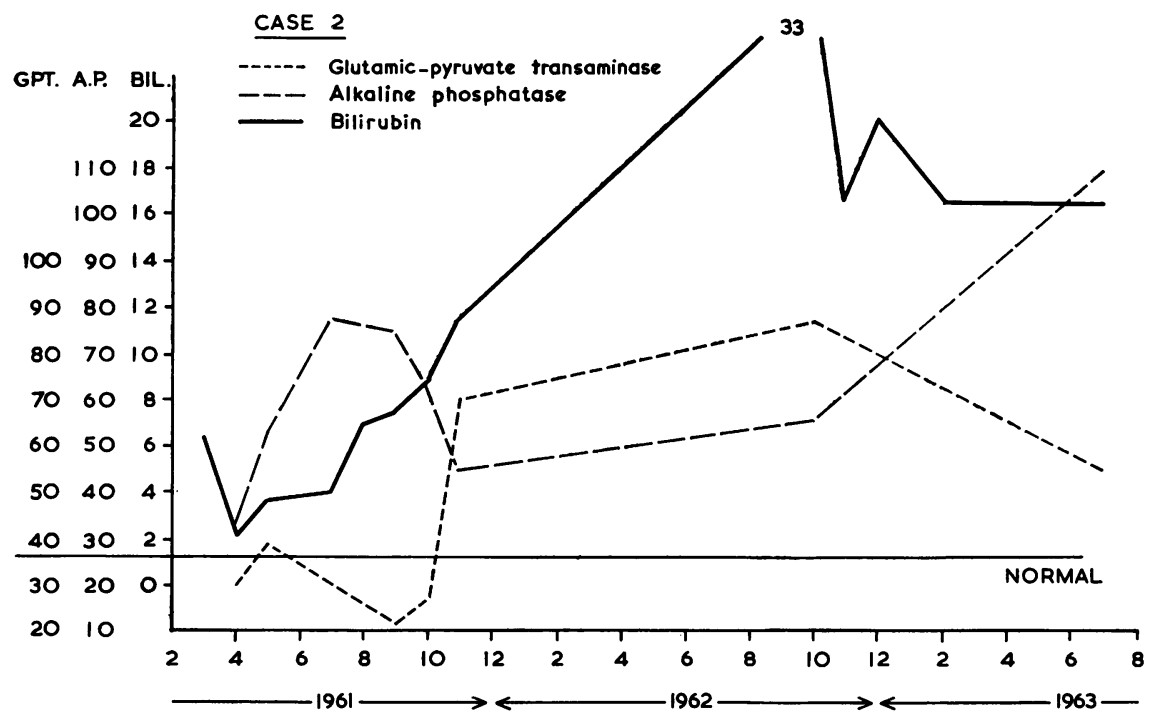

FIG. 5.-Changes in liver function tests of Case 2 with time age. 


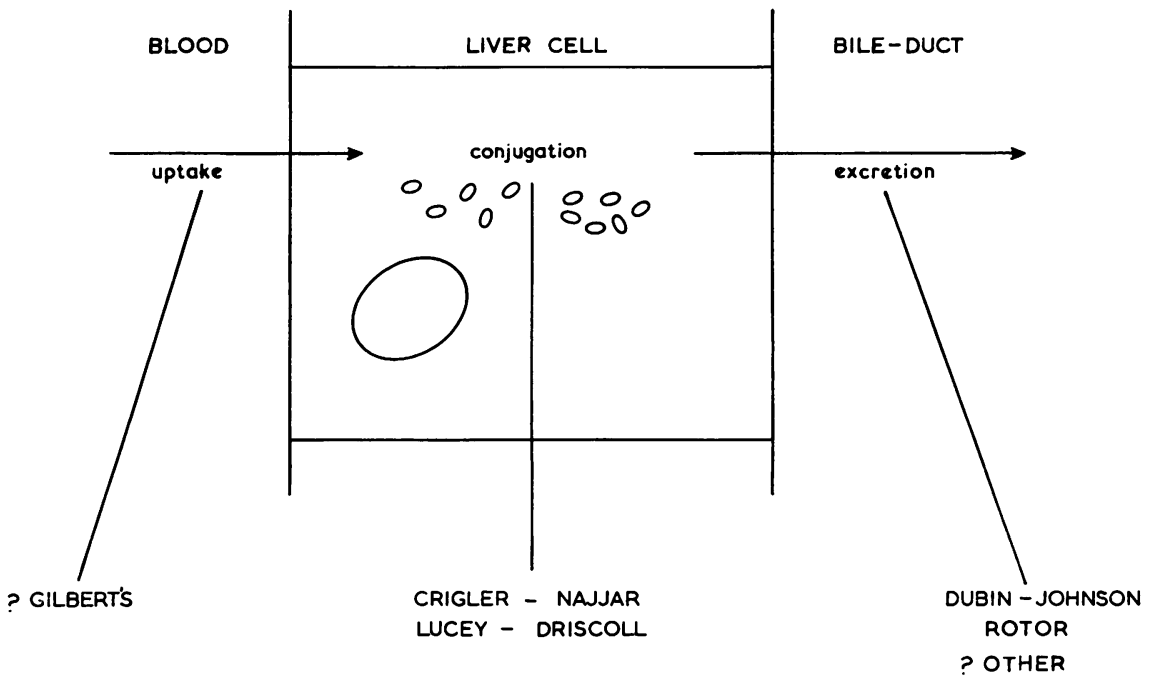

FIG. 6.-Representation of suggested sites of liver cell barriers to bilirubin excretion in the syndromes associated with intrahepatic cholestasis.

absorption-and low prothrombin level, therefore, could be due to absence of bile acids in the intestines. The marked bromsulphalein retention is due either to a failure of conjugation or excretion. It was impossible to do a prolonged BSP excretion and so determine which was the defective factor.

The enzyme results varied with time. Originally the alkaline phosphatase was only just above normal, but progressively increased with fluctuations back towards normal. The alkaline phosphatase, which is thought to be specific to the liver, is 5-nucleotidase: this was increased but not to levels reported in extrahepatic obstruction. The transaminases were normal at first but again tended to increase, though with marked fluctuations. The pseudocholinesterase was normal.

These results, together with the normal cholangiogram and the absence of significant bile-duct obstruction on microscopical examination, led us to place the defect at cellular level.

Congenital defects of bilirubin metabolism can be classified into the three main groups (Fig. 6). There may be a defect in transport across the liver cell membrane from the plasma to the liver cell (Gilbert's disease: Gilbert and Lereboullet, 1901). In the Crigler-Najiar syndrome (Crigler and Najiar, 1952) there is gross reduction of the conjugating enzymes. The Lucey-Driscoll syndrome (Arias and Wolfson) is due to an inhibition of conjugation by a substance thought to be pregnanediol derived from the mother's breast milk. In both these groups, the result is an accumulation of unconjugated bilirubin. Since our cases had a high proportion of conjugated bilirubin they belong to the third group where there is a defect in transport across the liver cell membrane from the liver cell to the bile canaliculus. Other syndromes which are thought to have defects at this point are Rotor's and Dubin-Johnson. The present cases differ from these clinically, in the laboratory findings and in the liver histology. The DubinJohnson and Rotor syndromes do not have pruritus, acholic stools, steatorrhoea, raised alkaline phosphatases, or bile stasis in the liver.

Congenital absence of the intrahepatic bile-ducts was described by Haas and Dobbs (1958), who recorded obstructive jaundice which started in the first week of life, but improved with time. The jaundice in the present two cases increased with age. Haas and Dobbs' cases had pruritus and normal extrahepatic biliary apparatus, like the present two sisters, but with absence of the intrahepatic bileducts. In their children the cholesterol level was very high-over $1,200 \mathrm{mg}$. $/ 100 \mathrm{ml}$, and in one reported case the serum lipids and lipoproteins also were raised. Both cases had xanthomata. The present sisters differ; they had no xanthomata, and the cholesterol levels were normal. A further differentiating feature is the absence of the bileducts in the portal tracts in intrahepatic bile-duct atresia. The portal bile-ducts were seen to be normal in our cases.

Recently 7 reported cases of a benign recurrent intrahepatic cholestasis have been summarized by Schapiro and Isselbacher (1963). In these patients there were recurrent episodes of cholestatic jaundice with pruritis, dark urine, acholic stools, and weight 
loss. The serum bilirubin levels were raised, and more than $50 \%$ was conjugated. The alkaline phosphatases were significantly raised, and the liver biopsies showed marked bile stasis and some cellular infiltration of the portal areas. Our cases were similar to these in biochemical features, but differed in the severity and progress of the disease. They are one of the few to be described with a definite family incidence.

Further studies, which included bilirubin and bromsulphalein excretion in idiopathic recurrent cholestasis, have been reported by Williams, Cartter, Sherlock, Scheuer, and Hill (1964). During an episode of jaundice the bromsulphalein was retained in excess amounts, but in the intervals between attacks the retention was normal. Injected bilirubin disappeared from the plasma at a normal rate, but conjugated bilirubin reappeared in excessive amounts indicating a block to excretion in the bile.

The clinical features of these four cases were very similar to those summarized by Schapiro and Isselbacher and differed from the present sisters not only in the age of onset and the course, but in the complete remission of jaundice and symptoms between attacks. The onset of the jaundice in the cases of Williams et al. was from 9-27 years. In none was there a family history, and these authors regarded the evidence of either an acquired or genetic defect to be inconclusive.

One of the puzzling features was the microscopical bile thrombi in some canaliculi. It seems most unlikely that these were due to canalicular obstruction as there was very little canalicular dilatation or other evidence to suggest obstruction at this site. The more likely explanation is that these thrombi were caused by alterations in bile solubility due to diminished bile acid excretion.

A striking and unique feature was the alteration of the liver histology in the two years between the biopsy and the necropsy. In this time the liver was permeated by a fine network of fibrous strands which distorted the lobules. It is likely that similar changes had affected the sister's liver, for she too died with ascites. The relatively rapid and extensive fibrosis could be due to the original disease process or possibly secondary to slow bile flow. Schaffner and Popper (1959) showed that either intrahepatic or extrahepatic cholestasis caused alterations in the micro-villi of the bile canaliculi and dilatation of the canaliculi. Steiner and Carruthers (1961) suggested that the micro-villi might be further damaged by prolonged contact with the bile in the canaliculi. It is possible, therefore, that the damaging effect of bile stasis could extend to structures adjacent to the canaliculi and cause a reactive fibrosis. The aetiology of the disease is unknown, but it is very likely to be genetic. The early onset, identical courses, and familial nature suggest a fundamental inherited biochemical lesion.

Although it was not possible to alter the clinical course by treatment, it was hoped to alleviate the most distressing feature of constant itching. When other substances failed, cholestyramine, which is a bile salt sequestrating resin, was given in an attempt to bind what little bile salts reached the intestines. The bile acid estimations in the blood showed that their concentration was reduced by the cholestyramine. The fact that there was little apparent benefit might be due to bile acids remaining in the tissues or to habituation of the scratching. The child was too young a witness to acknowledge benefit she may have felt. Probably the treatment should have been given longer. It seems to be the only substance to have had a beneficial effect.

\section{Summary}

Two sisters had identical illnesses with obstructive jaundice from early infancy. The jaundice fluctuated but never completely disappeared. It was much worse after infections or operations, gradually deepening until the children died in their third year. The children were dwarfed, had severe itching, steatorrhoea, acholic stools, and bilirubinuria. A notable feature was the excess of lanugo hair. The biochemical features included the finding of $60 \%$ conjugated bilirubin in the serum, one-half of which was alkali stable. The serum enzymes were normal initially, but gradually rose with time. Cholesterol and proteins were normal but bromsulphalein retention was much increased. The total serum bile acids were raised and the fractions were consistent with obstructive jaundice. Cholestyramine orally reduced the serum bile acids but did not seem to improve the pruritus. The biliary apparatus was normally patent. The initial liver biopsies were essentially normal, and the obstruction to bile flow was thought to be at the liver cell level. The liver histology had changed considerably in the two years between the examinations. Fine fibrous trabeculae developed in the liver substance. These two daughters of unrelated parents had a variety of obstructive jaundice not previously described.

We wish to thank Professor Watkins and Dr. P. T. Bray for their help in preparing this paper, Dr. William Davies and Dr. H. Coll for referring the children, Dr. T. E. Parry and Dr. F. K. Storring for reporting on the necropsy and biopsy specimens, Mr. R. W. Evans for photomicrographs, Miss Susan Bell, for the typescript, and Dr. J. J. F. Merry, of Merck, Sharpe, and 
Dohme, who very kindly supplied the cholestyramine. These cases were briefly described at the Fifth International Congress on Clinical Chemistry, Detroit, 1963.

\section{REFERENCES}

Arias, I. M. (1961). Studies of chronic familial non-hemolytic jaundice with conjugated bilirubin in serum with and without unidentified pigment in the liver cells. Amer. F. Med., 31, 510.

, and Wolfson, S. (1960). Inhibition of bilirubin conjugation in vitro by serum from infants with transient familial hyperbilirubinaemia and serum from their mothers. Gastroenterology, 38, 797.

Carey, J. B., Jr. (1958). The serum trihydroxy-dihydroxy bile acid ratio in liver and biliary tract disease. F. clin. Invest., 37, 1494.

Crigler, J. F., Jr., and Najjar, V. A. (1952). Congenital familial nonhemolytic jaundice with kernicterus. Pediatrics, 10, 169.

Dubin, I. N., and Johnson, F. B. (1954). Chronic idiopathic jaundice with unidentified pigment in liver cells: a new clinicopathologic entity with a report of 12 cases. Medicine (Baltimore), 33, 155.
Gilbert, A., and Lereboullet, P. (1901). La cholémie simple familiale. Sem. méd. (Paris), 21, 241.

Haas, L., and Dobbs, R. H. (1958). Congenital absence of the intrahepatic bile ducts. Arch. Dis. Childh., 33, 396.

Rotor, A. B., Manahan, L., and Florentin, A. (1948). Familial nonhemolytic jaundice with direct Van den Bergh reaction. Acta med. philipp., 5(2), 37.

Schaffiner, F., and Popper, H. (1959). Morphologic studies of cholestasis. Gastroenterology, 37, 565.

Schapiro, R. H., and Isselbacher, K. J. (1963). Benign recurrent intrahepatic cholestasis. New Engl. F. Med., 268, 708.

Schiff, L., Billing, B. H., and Oikawa, Y. (1959). Familial nonhemolytic jaundice with conjugated bilirubin in the serum: a case study. ibid., 260, 1315.

Steiner, J. W., and Carruthers, J. S. (1961). Studies on the fine structure of the terminal branches of the biliary tree. II. Observations of pathologically altered bile canaliculi. Amer. F. Path., 39, 41.

Williams, R., Cartter, M. A., Sherlock, S., Scheuer, P. J., and Hill, K. R. (1964). Idiopathic recurrent cholestasis: a study of the functional and pathological lesions in four cases. Quart. $\mathcal{F}$. Med., 33, 387. 